\title{
Investigation of the impact using neuroanatomy specimens prepared using new anatomical techniques on students' learning
}

\author{
RUIZ, C. R.1, LIMA, N. B.2, CUNHA, R. H.3 and NASCIMENTO, S. R. R.4*
}

\author{
1PhD Morphological Sciences, Department of Human Anatomny, Metodista University of São Paulo, \\ Alfeu Tavares, 149, Rudge Ramos, CEP 09641-000, São Bernardo do Campo, SP, Brazil \\ 2Laboratory's technical assistant of human anatomy, Department of Human Anatomny, Metodista University of \\ São Paulo Alfeu Tavares, 149, Rudge Ramos, CEP 09641-000, São Bernardo do Campo, SP, Brazil \\ 3Laboratory's technical assistant of human anatomy, Department of Human Anatomny, Metodista University of \\ São Paulo Alfeu Tavares, 149, Rudge Ramos, CEP 09641-000, São Bernardo do Campo, SP, Brazil \\ 4Postgraduate in macroscopic anatomy and anatomy by radiological imaging, Department of Human Anatomny, \\ São Camilo University Center, Avenida Nazare, 1501, Ipiranga, CEP 04263-100, São Paulo, SP, Brazil
}

*E-mail: riosnascimento@uol.com.br

\begin{abstract}
Introduction: Neuroanatomy specimens have greater fragility than other anatomy specimens and their useful life depends on good conditioning and protection. The difficulty in obtaining human specimens has increased the demand for preparations that might make such specimens more durable. Objective: transform the collection of neuroanatomy specimens in the anatomy laboratory into specimens that were more instructive for students, through more refined anatomical techniques, thereby improving the appearance and preservation of these specimens, and also to develop a scientific study on the importance of this type of didactic-pedagogical tool. Material and Methods: After preparing the specimens and using them in the classroom, we applied a questionnaire to evaluate the learning process, with regard to ease of handling the specimens, improvement of instruction and construction of knowledge. We gathered responses from 53 students in their fourth teaching semester of the biomedicine course at the Methodist University of São Paulo. Results: after the treatment to clarify and demarcate anatomical structures in the neuroanatomical specimens that was put forward in this study, an effective improvement in the students' study method was demonstrated (100\%). Conclusions: The objectives proposed by the discipline were achieved in terms of yield (92.5\%) and understanding of theory during practical classes $(98 \%)$, thus generating student behavior that was more positive. In relation to handling and discomfort relating to the smell of the old specimens, there was an improvement of $88.7 \%$ through using the current specimens. There was also an improvement in learning outside of the classroom hours $(86.4 \%)$.
\end{abstract}

Keywords: anatomy teaching, neuroanatomy, anatomical preparations.

\section{Introduction}

Use of anatomical specimens is a privilege that not all undergraduate and postgraduate students have, given the enormous difficulty in obtaining them and the length of their useful life, which relates to the methods used for specimen preparation and maintenance.

Out of all the anatomical specimens, neuroanatomy specimens have the greatest fragility, and their useful life depends on good conditioning and protection. The difficulty in obtaining human specimens for teaching neuroanatomy has increased the demand for preparations that enable greater durability for them (BAERES and MULLER, 2001). Some techniques for preparing anatomical specimens for teaching macroscopic anatomy have become established in the literature, and there is no doubt that these have greatly facilitated preservation of these specimens and students' learning (BRAAK, 1978; GERFEN, 2003; MAGIROS, KEKIC and DORAN, 1997).

Several techniques for conserving the encephalon have been used for many years, such as use of $20 \%$ formalin, renewed every 48 hours, with the aim of fixing the encephalon alone (RODRIGUES, 1998), or a 10\% formalin solution in which the anatomical specimens are left immersed for at least 10 days (PEREIRA and OLIVEIRA, 2010). Over the last decade, plastination, which enables extremely faithful viewing of neuroanatomical structures, has provided greater durability of the material. Through this, the characteristic smell of the formaldehyde traditionally used for specimen fixing is no longer present (BAERES and MULLER, 2001; LATORRE, GARCIA-SANZ, MORENO et al., 2007; JONES, 2002).

In addition to preservation in formalin, neuroanatomy specimens go through a more elaborate process, focused not only on fixing the specimen but also on increasing their useful life.

After fixing in formalin, neuroanatomy specimens are usually conditioned in vats. This procedure preserves the specimen from deterioration caused by microorganisms but it does not protect it from handling by students.

However, as reported by Gillingwater (2008), direct experience with human material is extremely important for ensuring that a deep understanding of anatomy is achieved, rather than just a superficial understanding. Moreover, nowadays, although knowledge of human anatomy is indispensable in training for any healthcare professional, 
severe reductions in the actual time available for this discipline (as measured in terms of timetabled hours) are being experienced. It can also be seen that changes aimed at integration of anatomy with other similar disciplines are sometimes necessary in order to achieve understanding of the practical applications of anatomical knowledge (KLUCHOVA, 2000; GILLINGWATER, 2008). Through the above factors, general reductions in the time available for students to interact with human material have been noted.

These events have simply increased the need for human specimens that are much more elaborate, with markings of a didactic-pedagogical nature accompanied by explanatory legends so that, within the reduced time available, students achieve greater comprehension of the anatomical structures (JOHNSON, CHARCHANTI and TROUPIS, 2012; PANI, CHARIKER and NAAZ, 2013). An investigation developed at the Mayo Medical School proved that having a list of structures during classes in the anatomy laboratory improved study quality and increased the positive results among the students. This type of initiative is viewed positively by students, which is thus a recommendation to use this tool (HOFER, NIKOLAUS and PAWLINA, 2011).

What we are now proposing with regard to conditioning for neuroanatomy specimens is that after fixing, specimens should then go through a clarifying method and then through a process of demarcation of the main anatomical structures, and lastly should be placed in transparent acrylic boxes, which should then be sealed. This procedure will decrease the loss of specimens to almost zero, along with the need to replace them, while at the same time transforming the specimens practically into images in an anatomy atlas. This will make it easier for the students to learn from the specimens, given that they will now be handling the boxes and not the specimens, and will not be exposed to formalin. It will in many cases allow them to study without the aid of an anatomy atlas. Identification of most of the structures visible on these specimens provides an excellent teaching resource, in comparison with specimens that have not received this treatment, and also has very positive acceptance among students (LATORRE, GARCIA-SANZ, MORENO et al., 2007; BAERES and MULLER, 2001). In previous experiences, this didactic-pedagogical tool has added quality to classes and has increased the conservation rate of specimens in the anatomy laboratory by almost $100 \%$.

The objective of this study was to transform the collection of neuroanatomy specimens at the anatomy laboratory on the Rudge Ramos campus, into specimens that were more instructive for the students, by means of anatomical techniques that were more refined, thereby improving the appearance and preservation of these specimens. Another objective was to develop a scientific study on the importance of this type of didactic-pedagogical tool, by means of tabulating the data obtained, thereby validating the improvement in students' learning from this type of specimen in comparison with previous specimens.

\section{Materials and Methods}

To clarify the specimens, they had to be immersed in a vat, in a mixture of cold water with $20 \%$ oxygenated water (130 volumes) or $20 \%$ hydrogen peroxide. Four days later, the specimens were removed from this vat and were washed in running water. To fix the specimens after washing in water abundantly, a $10 \%$ formalin solution was prepared and the specimens were immersed in this for 10 days. At the time of use, after this period, they were again washed in running water and then left to drip-dry on a sloping surface. After this, they were put into another vat containing water and $5 \%$ formalin (Figure 1).

Two types of marking for the anatomical structures were used. Firstly, for specimens that had already been glycerinated and did not have a good visual appearance, markings were painted on and the specimens were covered with a fixative varnish. The second type of marking was used for cleared specimens in formalin, in which strings were inserted between the sulci and gyri of the telencephalon to delimit them, and numbers were placed on the structures of greatest interest, thus making the specimens self-instructive (Figure 2). Each specimen was accompanied by a numbered guide that allowed students to find the name of the structure.

The boxes were sealed using fast-drying liquid glue after the anatomical specimen had been positioned and formalin solution had been added. For larger specimens, $40 \mathrm{ml}$ of formalin was used; for medium-sized specimens, $20 \mathrm{ml}$; and for smaller specimens, $5 \mathrm{ml}$, injected using a syringe through one corner of the box (Figure 3 ).

After the specimens had been prepared, they were used in practical classes for students in the fourth semester of the

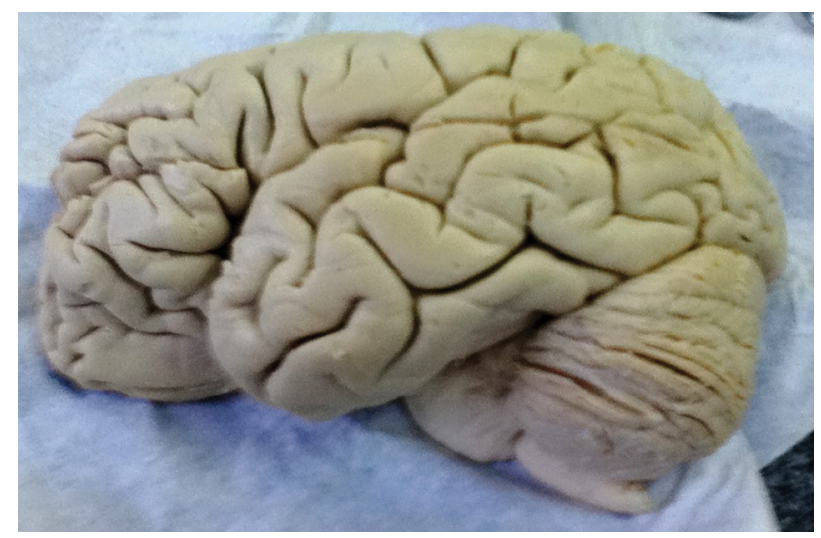

Figure 1. Anatomical piece after bleaching and before the step of marking.

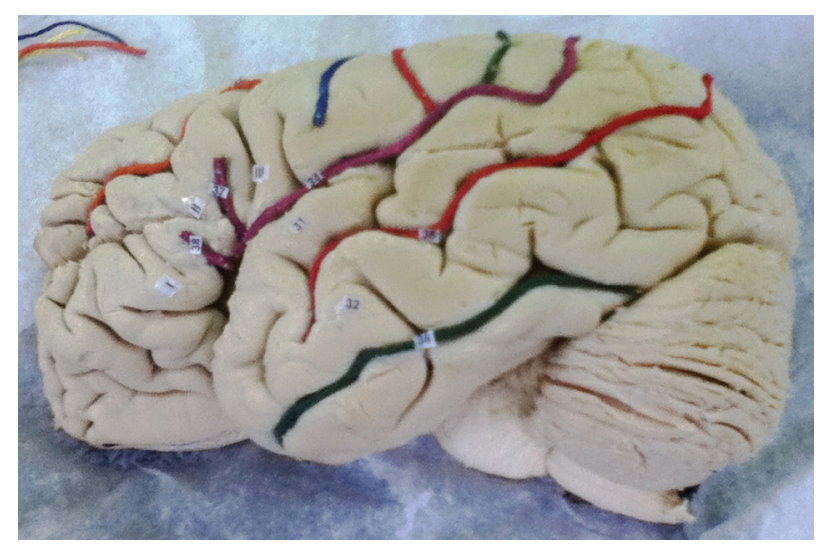

Figure 2. Anatomical piece after insertion of the markings of the anatomical structures of greatest interest. 
biomedicine course, who had previously been studying using others specimens without this preparation. These students then participated voluntarily in an investigation in which we determined their perceptions of the didactic-pedagogical changes caused by the changes to the specimens. The aim was to measure the extent to which the specimens prepared had generated attitudes among students that were more positive and had improved their learning, through the students' opinions and the yield from the discipline. The measurements were made by means of a questionnaire containing a multiple-choice test that compared the viewing of the anatomical structures learned previously from the specimens without preparation, with the viewing of the same structures now from the prepared specimens.

The questionnaire evaluating the students' learning comprised 10 questions on the ease of handling of the specimens, improvement of instructive qualities and facilitation of knowledge construction.

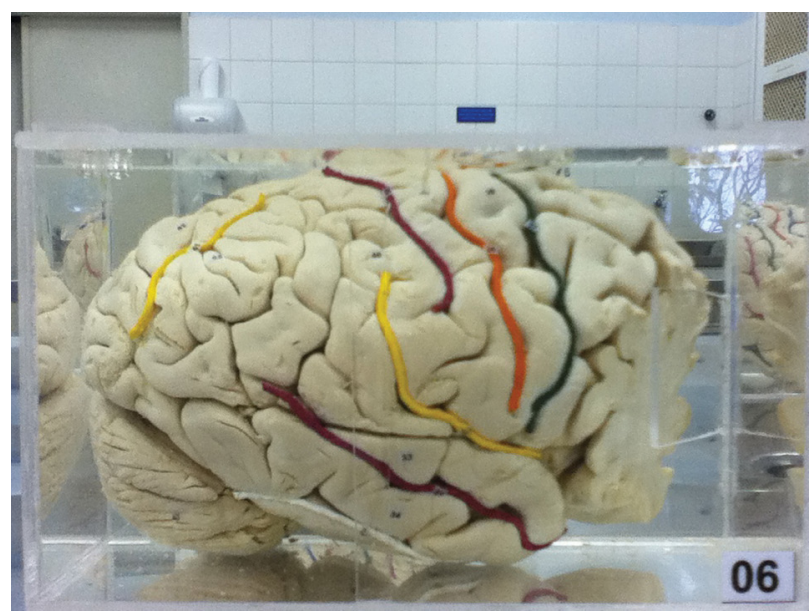

Figure 3. Anatomical piece after placing in acrylic box.
Responses were only gathered from students on the biomedicine course at the Methodist University of São Paulo who had attended more than $50 \%$ of the classes during the semester. Our sample thus comprised 53 student respondents, from both the morning and evening groups.

\section{Results and Discussion}

The results obtained from gathering the responses to the questionnaire that was applied to the students are described in the following Table 1:

The following other comments were attached to the questionnaires: comparing the new specimens with the specimens used on the first occasion on which the students had been in contact with the neuroanatomy material, $94.3 \%$ of the students considered that there had been a great change in the study method. Out of the total number of respondents, $96.2 \%$ agreed that there was a great difference between the current specimens and the previous specimens.

Upon being asked to give a score between 0 and 10 to the specimens used in the current semester, the percentage of the scores that were between 7.0 and 8.0 was $5.67 \%$ and the percentage of the scores that were between 8.0 and 10.0 was $94.33 \%$. The maximum score of 10.0 was given in $71.7 \%$ of the responses.

With regard to the score given for the learning achieved from the specimens used during the current semester, the percentage of the scores between 5.0 and 6.0 was $3.78 \%$; between 6.0 and 8.0 was $58.48 \%$; and between 8.0 and 10.0 was $37.74 \%$. The score with the highest percentage $(32.07 \%)$ was 8.0 .

These results show that Latorre, Garcia-Sanz, Moreno et al. (2007) and Baeres and Muller (2001) were coherent in their reports on the positive reaction shown by students towards instructive techniques or tools that prioritize more effective learning on human anatomy. As reported by Kluchova (2000) and Gillingwater (2008), changes to the

Table 1. Results obtained from the students.

\section{GREAT \\ CONTRIBUTION}

\section{VERY GREAT CONTRIBUTION}

\section{LITTLE OR NO \\ CONTRIBUTION OR NO RESPONSE}

Current specimens in relation to the old specimens, with regard to studying

Identification of anatomical structures done on the specimen

Use of numbered lists of anatomical structures that accompany the specimens

Decreased discomfort in handling, and in relation to the smell of the formalinfixed specimens

Understanding of the theory given in the classroom and comprehension of this in the practical class

Yield from class
$60 \%$

$28.3 \%$

$22.6 \%$

$47 \%$

$51 \%$

$37.7 \%$

$2.3 \%$

$$
67.9 \%
$$

$$
69.6 \%
$$

$$
66.1 \%
$$

(n)

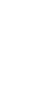

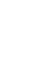


teaching-learning process are welcome, provided that they are guided by serious studies and foundations, as well as institutional support for carrying out such changes.

\section{Conclusions}

After the clarifying treatmentanddemarcation ofanatomical structures that were proposed for the neuroanatomy specimens in this study, an effective improvement of the students' study method was demonstrated (100\%). The objectives proposed by the discipline were achieved in terms of yield $(92.5 \%)$ and understanding of theory during practical classes (98\%), thus generating student behavior that was more positive. In relation to handling and discomfort relating to the smell of the old specimens, there was an improvement of $88.7 \%$ through using the current specimens. There was also an improvement in learning outside of the classroom hours $(86.4 \%)$.

\section{References}

BAERES, FM. and MOLLER, M. Plastination of dissected brain specimens and Mulligan-stained sections of the human brain. European Journal of Morphology., 2001, vol. 39, n. 5, p. 307-311. PMid:12221512. http://dx.doi.org/10.1076/ejom.39.5.0307

BRAAK, H. Simple and durable staining of thick sections of the human brain for macroscopic study. Stain Technology, 1978, vol. 53, n. 2 , p. $87-89$. PMid:80847

GERFEN, CR. Basic neuroanatomical methods. Current Protocols in Neuroscience, 2003. Chapter 1: Unit 1.1. http://dx.doi. org/10.1002/0471142301.ns0101s23

GILLINGWATER, TH. The importance of exposure to human material in anatomical education: a philosophical perspective. Anatomical Sciences Education, 2008, v. 1, n. 6, p. 264-266. PMid:19109856. http://dx.doi.org/10.1002/ase.52
HOFER, E., NIKOLAUS, OB. and PAWLINA, W. Using checklists in a gross anatomy laboratory improves learning outcomes. Anatomical Sciences Education, 2011, v. 4, n. 5, p. 249-255. PMid:21786427. http://dx.doi.org/10.1002/ase.243

JOHNSON, EO., CHARCHANTI, AV. and TROUPIS, TG. Modernization of an anatomy class: from conceptualization to implementation: a case for integrated multimodal-multidisciplinary teaching. Anatomical Sciences Education, 2012, vol. 5. n. 6, p. 354366. PMid:22730175. http://dx.doi.org/10.1002/ase.1296

JONES, DG. Re-inventing anatomy: the impact of plastination on how we see the human body. Clinical Anatomy, 2002, vol. 15, n. 6, p. $436-440$

KLUCHOVA, D. New pedagogic methods in anatomy: experience at Cambridge University. Bratislavske Lekarske Listy, 2000, vol. 101, n. 1, p. 58-60. PMID: 10824417

LATORRE, RM., GARCIA-SANZ, MP., MORENO, M., HERNANDEZ, F., GIL, F., LOPEZ, O., AYALA, MD., RAMIREZ, G., VAZQUEZ, JM., ARENCIBIA, A. and HENRY, RW. How useful is plastination in learning anatomy? Journal of Veterinary Medical Education, 2007, vol. 34, n. 2, p. 172-176. PMid:17446645

MAGIROS, M., KEKIC, M. and DORAN, GA. Learning relational anatomy by correlating thin plastinated sections and magnetic resonance imaging: preparation of specimens. Acta Anatomica (Basel), 1997, vol. 158, n. 1, p. 37-43. http://dx.doi. org/10.1159/000147908

PANI, JR., CHARIKER, JH. and NAAZ, F. Computer-based learning: interleaving whole and sectional representation of neuroanatomy. Anatomical Sciences Education, 2013, vol. 6, n. 1, p. 11-18. PMid:22761001. http://dx.doi.org/10.1002/ase.1297

PEREIRA, LA. and OLIVEIRA, LA. Apostila de técnicas anatômicas. São Paulo: Centro Universitário São Camilo, 2010.

RODRIGUES, H. Técnicas anatômicas. 2. ed. Vitória: [s.n.], 1998.

Received Dec. 1, 2013 Accepted Dec. 15, 2014 